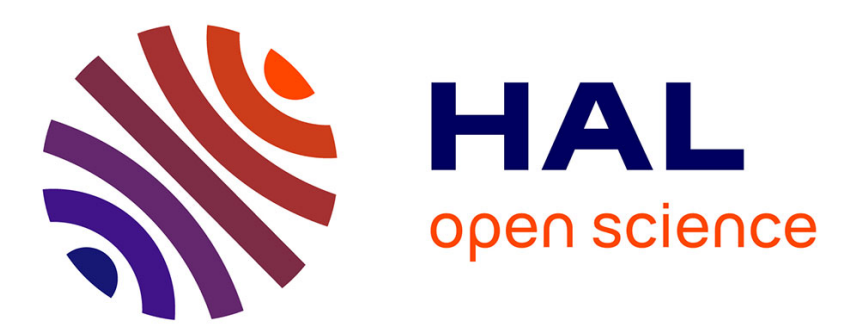

\title{
Influence of Dealumination by Acetylacetone on Acidity and Activity of Amorphous Silica-Aluminas
}

Xiaojing Jin, Yannick Millot, Céline Sayag, Juliette Blanchard, Pascal Ping Man

\section{- To cite this version:}

Xiaojing Jin, Yannick Millot, Céline Sayag, Juliette Blanchard, Pascal Ping Man. Influence of Dealumination by Acetylacetone on Acidity and Activity of Amorphous Silica-Aluminas. ChemistrySelect, 2020, 5 (8), pp.2489-2495. 10.1002/slct.201904712 . hal-02919070

\section{HAL Id: hal-02919070 \\ https: / hal.sorbonne-universite.fr/hal-02919070}

Submitted on 21 Aug 2020

HAL is a multi-disciplinary open access archive for the deposit and dissemination of scientific research documents, whether they are published or not. The documents may come from teaching and research institutions in France or abroad, or from public or private research centers.
L'archive ouverte pluridisciplinaire HAL, est destinée au dépôt et à la diffusion de documents scientifiques de niveau recherche, publiés ou non, émanant des établissements d'enseignement et de recherche français ou étrangers, des laboratoires publics ou privés. 


\title{
Influence of Dealumination by Acetylacetone on Acidity and Activity of Amorphous Silica-Aluminas
}

\author{
Xiaojing Jin ${ }^{[a, b]}$, Yannick Millot ${ }^{[a]}$, Céline Sayag ${ }^{[a]}$, Juliette Blanchard ${ }^{[a] *}$, Pascal P. Man ${ }^{[\mathrm{c}]}$ \\ [a] Dr. X. Jing, Dr. Y. Millot, Dr. C. Sayag, Dr. J. Blanchard \\ Laboratoire de Réactivité de Surface, LRS UMR 7197 \\ Sorbonne Université, CNRS \\ F-75005 Paris, France \\ E-mail: Juliette.blanchard@sorbonne-universite.fr \\ [b] Dr. X. Jing \\ Department Guangdong Provincial Key Laboratory of Atmospheric Environment and Pollution Control, School of Environment and Energy, \\ South China University of Technology \\ Guangzhou, 510006, China \\ [c] Dr. P. P. Man \\ Institut des Matériaux de Paris-Centre \\ Sorbonne Université, CNRS \\ F-75005 Paris, France \\ Supporting information for this article is given via a link at the end of the document
}

\begin{abstract}
The influence of dealumination of two commercial amorphous silica-aluminas (ASAs) with acetylacetone on their textural properties, acidity and catalytic activity was studied by $\mathrm{N}_{2-}$ sorption, $\mathrm{NH}_{3}$-TPD, FTIR of adsorbed pyridine as well as ${ }^{1} \mathrm{H}$ and ${ }^{27} \mathrm{Al}$ MAS NMR. Acetylacetone treatment increases the pore volume and surface area $(+20 \rightarrow+30 \%)$ of commercial ASA without changing the pore size. More than half of the Al species are extracted from ASA but the total acidity is preserved or even slightly increased (for the ASA with higher Al content). The percentage of acidic $\mathrm{Al}$ is increased by a factor 2. Dealumination results in a better access to acid sites and an increase of medium Brønsted acid sites (BAS), leading to a 1.5 higher catalytic activity for 3,3-Dimethyl-1-butene (33DMB1) isomerization.
\end{abstract}

\section{Introduction}

Amorphous silica-aluminas (ASA) are of considerable practical importance in industrial catalysis, where they are applied as a solid acid ${ }^{1}$ or serve as supports for finely dispersed metal sulfides or metals in a wide range of processes. ${ }^{2,3}$ ASA are frequently present in modern bifunctional metal/acid catalysts to enhance selectivity toward middle distillates from hydrocracking of heavy oil fractions. ${ }^{4}$ Compared to zeolites, ASA possess weaker and fewer Brønsted acid sites (BAS), and the structure of these sites are still subject to debate due to the amorphous nature of these materials. On ASA, the proportion of acid sites per Al is generally below 1 and many of these sites are Lewis acid sites (LAS).

Dealumination is one of the available methods to remove the ineffective Al species from aluminosilicates. For zeolites with low $\mathrm{Si} / \mathrm{Al}$ ratio (e.g. faujasite $\mathrm{Y}$ ), dealumination is commonly used to improve the stability of the zeolite and enhance its activity. Dealumination not only improves the stability of the framework by increasing the Si/Al ratio, ${ }^{5,6}$ but also generates a secondary porosity made of mesopores that increases significantly the accessibility of the acid sites and hence alleviate diffusion limitations and improves catalytic activity. ${ }^{7}$ A significant number of papers have been dedicated to the effect of dealumination of zeolite on their acidity. In general, it was found that severe dealumination decreases both Brønsted and Lewis acid sites, the former by removal of $\mathrm{Al}$ from the lattice by hydrolysis ${ }^{8}$ and the latter by condensation of alumina moieties. ${ }^{9}$

Dealumination process is rather complicated, as many thermodynamic or kinetic factors will affect it significantly depending on the experimental conditions. ${ }^{10}$ Dealumination can be achieved by steaming ${ }^{11}$, leaching with acids ${ }^{12}$, treatment with chelating agents such as hexafluorosilicate ${ }^{7,}{ }^{13}$, ammonium hydrogen difluoride $\left(\mathrm{NH}_{4} \mathrm{HF}_{2}\right)^{14}$, ethylenediamine tetracetic acid 15,16 , acetylacetone ${ }^{17-19}$ and many others. Acetylacetone as a bidentate and nonacidic ligand is a suitable agent for mild dealumination leading to the extraction of "loosely bond" aluminum atoms in zeolites. ${ }^{7,18,20}$ The product of dealumination $\left(\mathrm{Al}(\mathrm{acac})_{3}\right)$ can be washed out from parent sample. Its extraction will depend on the type of structure, pore opening and extent of guest-host interaction. ${ }^{20,21}$

Compared to zeolites, dealumination of ASAs has been far less investigated. Effect of dealumination of ASAs by hydrochloric acid was studied by nuclear magnetic resonance. ${ }^{22} \mathrm{~A}$ preferentially removal of octahedral aluminum was observed that occurred without modification of the catalytic properties. ${ }^{22}$ Dealumination of Al-MCM-41 type silica-alumina in basic media has also been reported. ${ }^{23}$

In the present study, we explored the dealumination of commercial ASA with acetylacetone, and proposed optimized dealumination conditions using this molecule. The influence of dealumination on the textural properties, acidity and catalytic activity was also studied and the nature of Al species that are removed during dealumination was investigated using ${ }^{27} \mathrm{Al}$ MAS NMR and FTIR.

\section{Results and Discussion}

\section{Textural properties}

Aluminum contents of the ASAs prepared by dealumination with acetylacetone under various conditions are reported in Table 1. Treatment with acetylacetone results in various degrees of dealumination depending on experimental conditions. At room temperature (LT series), for the samples prepared by subjecting 
SA13 $\left(\mathrm{NH}_{4}^{+}\right)$to acetylacetone treatment during $1 \mathrm{~h}$ (entry 2), only a small amount of aluminum was removed and extending time to $4 \mathrm{~h}$ (entry 3), did not bring any change. This indicates that acetylacetone dealumination ability under ambient conditions is limited. The negligible amount of extracted Al in ASA under these conditions is consistent with previous reports on zeolites. ${ }^{19,21}$ On the other side, after treatment at high temperature (HT series), dealumination is obvious: more than half of aluminum was removed from SA13 $\left(\mathrm{NH}_{4}{ }^{+}\right)$after reflux at $100^{\circ} \mathrm{C}$ during $4 \mathrm{~h}$ (entry 4). When prolonging time to $24 \mathrm{~h}$ (entry 5 ), only a very small extra amount of $\mathrm{Al}$ was further extracted, indicating that the plateau in the dealumination was almost already reached after $4 \mathrm{~h}$ (all the reactive $\mathrm{Al}$ atoms are removed within $4 \mathrm{~h}$ ). Therefore, optimal dealumination conditions are $4 \mathrm{~h}$ at $100^{\circ} \mathrm{C}$. When increasing the Al content in the starting ASA $\left(\mathrm{SA} 25\left(\mathrm{NH}_{4}^{+}\right)\right.$series, entries 7 \& 8), the fraction of extracted Al significantly increases (from $52 \%$ for $\mathrm{SA} 13\left(\mathrm{NH}_{4}{ }^{+}\right)$to $65 \%$ for SA25 $\left(\mathrm{NH}_{4}{ }^{+}\right)$under similar experimental conditions). Dealumination of calcined samples (SA13-H and SA25-H) was also attempted (entries 6 and 9). For the two calcined ASA, the extent of dealumination is less than for their ammonium form.

Table 1 Designation, Al content and textural properties of samples prepared by acetylacetone dealumination

\begin{tabular}{llllll}
\hline $\mathrm{n}^{\circ}$ & Sample $^{[\mathrm{a}]}$ & $\begin{array}{l}\text { Al } \\
(\mathrm{mmol} / \mathrm{g})\end{array}$ & $\begin{array}{l}\text { SBET } \\
\left(\mathrm{m}^{2} / \mathrm{g}\right)\end{array}$ & $\begin{array}{l}\text { Pore Size } \\
(\mathrm{nm})\end{array}$ & $\begin{array}{l}\text { Pore Volume } \\
\left(\mathrm{cm}^{3} / \mathrm{g}\right)\end{array}$ \\
\hline 1 & SA13-H & 2.3 & 445 & 4.8 & 0.70 \\
2 & SA13-LT-1h & 2.0 & 456 & 4.2 & 0.69 \\
3 & SA13-LT-4h & 2.0 & 491 & 4.2 & 0.71 \\
4 & SA13-HT-4h & 1.1 & 539 & 4.2 & 0.77 \\
5 & SA13-HT-24h & 1.0 & 550 & 3.7 & 0.77 \\
6 & SA13-H-HT-4h & 1.4 & 477 & 4.2 & 0.68 \\
7 & SA25-H & 4.0 & 421 & 4.8 & 0.70 \\
8 & SA25-HT-4h & 1.4 & 559 & 4.8 & 0.81 \\
9 & SA25-H-HT-4h & 1.7 & 477 & 4.8 & 0.71 \\
\hline
\end{tabular}

[a] details concerning the denominations of the samples are given in the experimental part in the supporting information.file.

To understand the effects of treatment with acetylacetone on the texture of the different samples, the porous properties of the dealuminated samples were compared (Table 1Table 1). It can be seen that, for treatments under ambient conditions of SA13 $\left(\mathrm{NH}_{4}{ }^{+}\right)$(entries, $2 \& 3$ ), no obvious effects of these treatments are observed. On the other side, for the samples obtained after reflux at $100^{\circ} \mathrm{C}$ during $4 \mathrm{~h}$ on the ammonium forms of the ASAs (entries 4 and 8), the surface area and the pore volume increase significantly compared to those of the starting ASA and the increase is more pronounced for the ASA undergoing the most important dealumination (surface area $+20 \%$ for SA13-HT-4h, $+33 \%$ for SA25-HT-4h). When dealumination is performed on the $\mathrm{H}$-form of ASAs under the same conditions (entries $6 \& 9$ ), the surface area also increases but to a lower extent and the pore volume changes only slightly.
Figure SI 1 shows the nitrogen adsorption-desorption isotherms and pore size distribution curves of the samples synthesized under optimal dealumination conditions. All samples exhibit a type IV isotherm with a type $\mathrm{H} 1$ hysteresis loop, which are characteristic of mesoporous materials with a relatively narrow pore size distribution. Dealumination with acetylacetone did not change the pore size distribution, indicating that removal of the aluminum species occurs without destroying the pore structure. Moreover, the increase of surface area cannot be solely assigned to the change of sample weight associated with the removal of $\mathrm{Al}$ (for the $\mathrm{SA} 13$ series, the weight percent of $\mathrm{Al}_{2} \mathrm{O}_{3}$ decreases from $13 \mathrm{wt} \%(2.3 \mathrm{mmol} / \mathrm{g}$, entry 1 of Table 1$)$ to $6 \mathrm{wt} \%(1.1 \mathrm{mmol} / \mathrm{g}$, entry 4) whereas for SA25, it decreases from $25 \mathrm{wt} \%$ (4 mmol/g, entry 7) to $8 \mathrm{wt} \%(1.4 \mathrm{mmol} / \mathrm{g}$, entry 8$))$. Hence, a possible explanation for the increase of the surface area is the removal of Al debris that were blocking the porosity, as previously reported by Fan et al. for the dealumination of steamed H-ZSM- 5 by citric acid. ${ }^{24}$

\section{Acidic Properties}

FTIR of adsorbed pyridine was used in order to differentiate the various acid sites present on the surface of the ASAs and assess the evolution of the acidity upon dealumination. The evolution of the pyridine vibration bands for spectra recorded at different temperature are shown on Figure 1 for sample SA13-HT-4h. For the $\mathrm{SA} 13$ series, the spectra recorded after desorption at $150^{\circ} \mathrm{C}$ are shown on Figure SI 2. The band at $1597 \mathrm{~cm}^{-1}$ on the spectrum recorded at $\mathrm{RT}$ is assigned to hydrogen bonded pyridine (weakly adsorbed pyridine). This band completely disappears upon thermal treatment. The bands at 1622 and $1450 \mathrm{~cm}^{-1}$ correspond to pyridine coordinated to LAS. The shoulder at $1640 \mathrm{~cm}^{-1}$ and the band at $1549 \mathrm{~cm}^{-1}$ are characteristic of pyridinium ions, indicating the chemisorption of pyridine on BAS. ${ }^{25}$ The IR band at around $1622 \mathrm{~cm}^{-1}$, associated to Lewis sites, shifts to higher frequency $\left(1624 \mathrm{~cm}^{-1}\right)$ when the temperature of desorption increases. It is generally admitted that the band at higher frequency represents Lewis sites of a higher acid strength. ${ }^{26} \mathrm{It}$ is worth mentioning that a new peak appears at $1462 \mathrm{~cm}^{-1}$ (which is clearly visible on the spectrum recorded at $350^{\circ} \mathrm{C}$ ). This band has been assigned by Flego et al. to a pyridine molecule interacting simultaneously with a Lewis site and a silanol. ${ }^{27}$

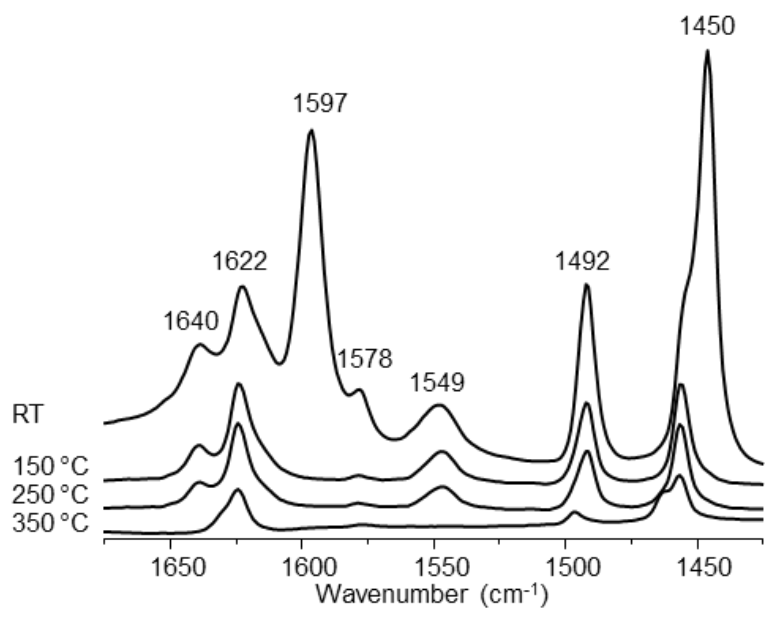

Figure 1 FTIR spectra of adsorbed pyridine on SA13-HT-4h after evacuation at different temperatures 
The bands at 1549 and $1457 \mathrm{~cm}^{-1}$ were used to quantify the amount of Brønsted and Lewis acid sites, respectively. The evolution of the intensities of these bands with desorption temperature $\left(150,250\right.$ and $\left.350^{\circ} \mathrm{C}\right)$ was used to evaluate the amount of total, medium+strong and strong acid sites (this delimitation is, of course, arbitrary as there is likely a continuum of acid strength in this amorphous material). The concentrations of mild (temperature of desorption between 150 and $250^{\circ} \mathrm{C}$ ), medium (temperature of desorption between $250^{\circ} \mathrm{C}$ and $350^{\circ} \mathrm{C}$ ) and strong (temperature of desorption higher than $350^{\circ} \mathrm{C}$ ) Lewis and Brønsted acid sites are reported in Table 2. When the temperature reaches $350^{\circ} \mathrm{C}$, the band at around $1456 \mathrm{~cm}^{-1}$ remains while the band at $1549 \mathrm{~cm}^{-1}$ vanishes. This indicates the presence of strong LAS and absence of strong BAS.

Table 2 Acid type and strength distribution of the samples determined by pyridine-IR

\begin{tabular}{|c|c|c|c|c|c|c|c|c|c|}
\hline \multirow{3}{*}{ Sample } & \multicolumn{8}{|c|}{ Acidity $(\mu \mathrm{mol} / \mathrm{g})$} & \multirow{3}{*}{$\begin{array}{c}\text { Acidic Al } \\
(\%)\end{array}$} \\
\hline & \multirow{2}{*}{$\begin{array}{l}\text { Total } \\
\mathrm{B}+\mathrm{L}\end{array}$} & \multicolumn{3}{|c|}{ BAS } & \multicolumn{3}{|c|}{ LAS } & & \\
\hline & & weak & medium & total & weak & medium & trong & total & \\
\hline SA13-H & 101 & 23 & 11 & 34 & 21 & 11 & 36 & 67 & 4.4 \\
\hline SA13-HT-4h & 102 & 11 & 25 & 35 & 10 & 13 & 43 & 67 & 9.2 \\
\hline SA13-H-HT-4h & 84 & 24 & 6 & 31 & 10 & 9 & 33 & 53 & 6.1 \\
\hline SA25-H & 110 & 31 & 10 & 40 & 21 & 9 & 40 & 70 & 2.8 \\
\hline SA25-HT-4h & 121 & 28 & 13 & 41 & 27 & 8 & 44 & 79 & 8.8 \\
\hline SA25-H-HT-4h & 94 & 25 & 10 & 36 & 14 & 6 & 38 & 58 & 5.4 \\
\hline
\end{tabular}

Total acidity of SA25-H is hardly higher than that of $\mathrm{SA} 13-\mathrm{H}$. Considering that the aluminum content is almost twice higher, this indicates that the fraction of non-acidic Al is much higher in SA25$\mathrm{H}$ than in SA13-H.

Starting from $\mathrm{SA} 13\left(\mathrm{NH}_{4}{ }^{+}\right)$, mild dealumination with acetylacetone (SA13-HT-4h) removes half of the aluminum species, but this removal occurs without modification in the total number of acid sites, indicating that acetylacetone removes selectively non acidic aluminum while preserving the acidic ones. It is consistent with previous results from the literature regarding dealumination of zeolite. ${ }^{7}$ Quite interestingly, mild dealumination increases medium BAS and strong LAS. This indicates that the removal of non-acidic aluminum affects positively the acidic properties of the ASA. A possible explanation would be that the removal of nonacidic aluminum in the close vicinity of acidic ones modifies their acidic properties. For the dealuminated samples prepared by using the $\mathrm{H}$ form of ASAs (samples SA13-H-HT-4h and SA25-H$\mathrm{HT}-4 \mathrm{~h}$ ), a decrease of the total acidity occurs, indicating that dealumination may be less selective when applied to the $\mathrm{H}$ form than on the ammonium one. For all ASA and whatever the dealumination conditions, strong BAS are never detected, while the Lewis acidity is dominated by strong sites.

Dealumination with acetylacetone results in an important increase in the effective acidity (percentage of acid sites per Al), that can reach a factor of two (SA13-HT-4h compared to SA13-H) and even three (SA25-HT-4h compared to SA25-H). The more important increase in effective acidity for the ASA obtained by dealumination of $\mathrm{SA} 25\left(\mathrm{NH}_{4}^{+}\right)$is consistent with the fact that $\mathrm{SA} 25-\mathrm{H}$ contains a higher fraction of non-acidic $\mathrm{Al}$, which makes dealumination more efficient on this sample than on $\mathrm{SA} 13\left(\mathrm{NH}_{4}{ }^{+}\right)$ (the dealuminated samples derived from these two ASAs have similar effective acidities). For the samples prepared by dealumination of the $\mathrm{H}$ form ASAs, the effective acidity increases only slightly as less Al was removed and total number of acid sites decreases.

\section{Catalytic Performance}

According to literature, 33DMB1 isomerization occurs through a purely protonic mechanism ${ }^{28-30}$ (Lewis acid sites are not involved in this reaction). Furthermore, 33DMB1 isomerization occurs over BAS with medium (or higher) acidic strength (corresponding to a pyridine desorption temperature of $220^{\circ} \mathrm{C}$ )..$^{31,32}$ It is therefore well suited for the characterization of the Brønsted acidity of ASAs. Figure 2 shows the conversion values as a function of time on stream for four of the ASA samples.

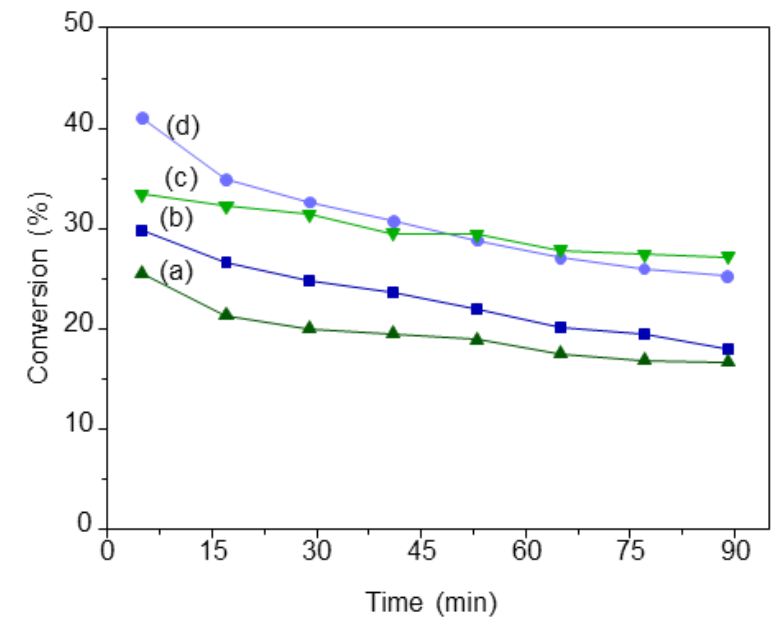

Figure 2 Conversion of 33DMB1 as a function of time on stream for (a) SA13$\mathrm{H}$, (b) SA25-H (c)SA13-HT-4h, (d)SA25-HT-4h 
For all samples, conversion decreases with time on stream and finally tends to stabilize. This deactivation is probably due to the deposition of coke owing to other secondary reactions. The conversion observed for dealuminated samples is, at steady state, about 1.5 times higher than that of their respective starting ASA. This increase may be related to the increase in the amount of medium Brønsted sites (Table 2), as 33DMB1 conversion is expected to be governed by BAS desorbing pyridine above $220^{\circ} \mathrm{C}$, and/or to changes in the textural properties (see Table 1).

\section{Aluminum coordination}

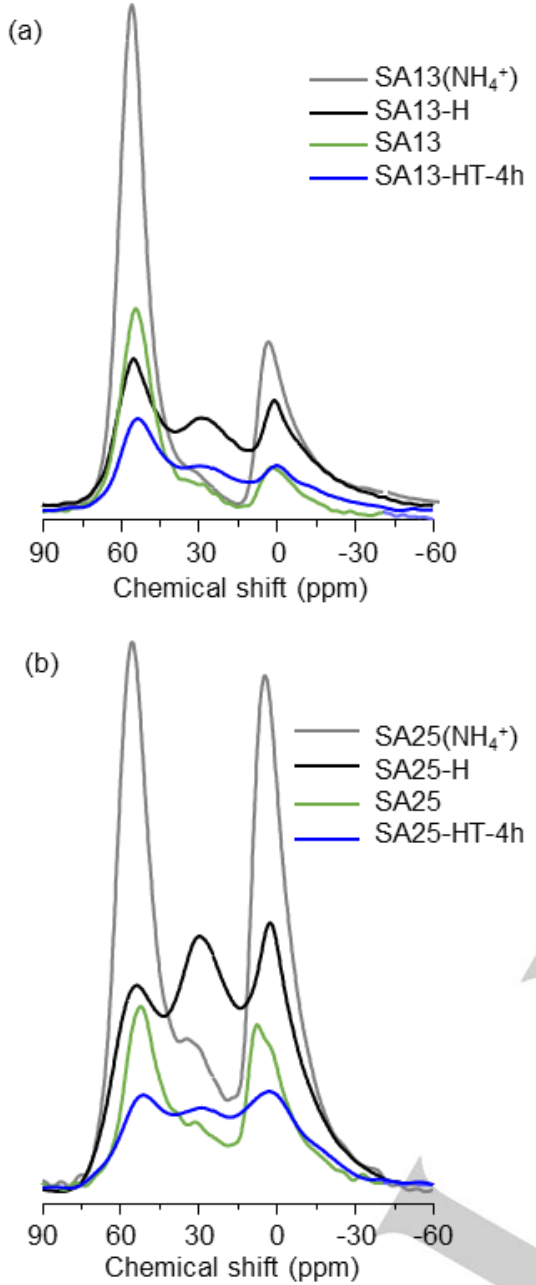

Figure $3{ }^{27}$ Al MAS NMR of starting ASAs and dealuminated samples: (a) SA13 series; (b) SA25 series.

In order to gain insight into the dealumination mechanism, ${ }^{27} \mathrm{Al}$ MAS NMR was used to characterize the samples, not only in their calcined form but also in their intermediate form (treated with acetylacetone then dried but uncalcined, signaled by the postfix (a)). Spectra are shown in Figure 3. For a quantitative comparison, appropriate data acquisition conditions were chosen and samples were rehydrated before measurement to allow detection of all Al atoms. ${ }^{33}$ Moreover, the amount of sample in the rotor was weighted and ${ }^{27} \mathrm{AI}$ NMR spectra were normalized based on this weight. By deconvoluting a spectrum, the contribution of each aluminum coordination to the NMR signal was determined and converted to a concentration of $\mathrm{Al}$, in $\mathrm{mmol}^{-\mathrm{g}^{-1}}$, based on the total Al loading (we verified that the evolution of the total $\mathrm{Al}$ area vs. the Al content -as determined by elemental analysis, see Table 1Table 1- was linear). The peak assignments and the concentration of each Al coordination are summarized in Table 3 The spectrum of $\mathrm{SA} 13\left(\mathrm{NH}_{4}{ }^{+}\right)$(uncalcined ammonium form, entry 1) shows two main peaks at 55.5 and $4.0 \mathrm{ppm}$, attributed to aluminum in tetrahedral $\left(\mathrm{Al}^{\mathrm{IV}}\right)$ and octahedral $\left(\mathrm{Al}^{\mathrm{VI}}\right)$ environment, respectively. The nonzero intensity between the two main lines indicates the probable presence of a weak amount of $\mathrm{Al}^{\mathrm{V}} .^{34}$ For SA25 $\left(\mathrm{NH}_{4}^{+}\right)$, (entry 5) with nearly twice more Al than SA13 $\left(\mathrm{NH}_{4}^{+}\right)$, the spectrum exhibits a similar intensity for $\mathrm{Al}^{\mathrm{IV}}$ whereas the intensity of the peak associated with $\mathrm{Al}^{\mathrm{VI}}$ increases significantly. Therefore, most of the increase in the $\mathrm{Al}$ content between SA13 $\left(\mathrm{NH}_{4}{ }^{+}\right)$and SA25 $\left(\mathrm{NH}_{4}{ }^{+}\right)$contributes to $\mathrm{Al}{ }^{\mathrm{VI}}$. Moreover, for $\mathrm{SA} 25\left(\mathrm{NH}_{4}{ }^{+}\right)$, the signal at ca. $30 \mathrm{ppm}$, associated to $\mathrm{Al}^{\mathrm{V}}$, is clearly visible between these two main lines.

Table 3 Concentration of surface hydroxyls (TGA) and distribution of aluminum species (based on the deconvolution of their normalized ${ }^{27} \mathrm{AI}$ MAS NMR spectra and recorded on rehydrated samples)

\begin{tabular}{|c|c|c|c|c|c|c|c|c|}
\hline \multirow{2}{*}{$n^{\circ}$} & \multirow{2}{*}{ Sample } & \multirow{2}{*}{$\begin{array}{c}\mathrm{OH} \\
(\mathrm{mmol} / \mathrm{g})\end{array}$} & \multicolumn{3}{|c|}{ Al percentage $(\%)$} & \multicolumn{3}{|c|}{ Al content $(\mathrm{mmol} / \mathrm{g})$} \\
\hline & & & $A l^{I V}$ & $\mathrm{Al}^{\mathrm{V}}$ & $\mathrm{Al}^{\mathrm{VI}}$ & $\mathrm{Al}^{\mathrm{IV}}$ & $\mathrm{Al}^{\mathrm{V}}$ & $\mathrm{Al}^{\mathrm{VI}}$ \\
\hline 1 & $\mathrm{SA} 13\left(\mathrm{NH}_{4}^{+}\right)$ & - & 65 & 4 & 32 & 1.5 & 0.1 & 0.7 \\
\hline 2 & SA13-HT-4h(a) & - & 67 & 7 & 27 & 0.7 & 0.1 & 0.3 \\
\hline 3 & SA13-HT-4h & 4.1 & 44 & 27 & 29 & 0.5 & 0.3 & 0.3 \\
\hline 4 & SA13-H & 3.5 & 30 & 39 & 30 & 0.7 & 0.9 & 0.7 \\
\hline 5 & $\mathrm{SA} 25\left(\mathrm{NH}_{4}{ }^{+}\right)$ & - & 45 & 4 & 51 & 1.8 & 0.1 & 2.1 \\
\hline 6 & SA25-HT-4h (a) & - & 43 & 6 & 52 & 0.6 & 0.1 & 0.7 \\
\hline 7 & SA25-HT-4h & 4.5 & 34 & 18 & 48 & 0.5 & 0.3 & 0.7 \\
\hline 8 & SA25-H & 3.6 & 27 & 31 & 43 & 1.1 & 1.2 & 1.7 \\
\hline
\end{tabular}

Calcination leads, for the two starting ASA (entries 4 and 8, SA13$\mathrm{H}$ and SA25-H samples), to a significant increase in the proportion of $\mathrm{Al}^{\mathrm{V}}$ at the expense of $\mathrm{Al}^{\mathrm{IV}}$. This modification in the speciation of Al between the $\mathrm{H}$ form and the $\mathrm{NH}_{4}$ form is probably related to the flexible coordination of some of the Al atoms in ASA, which has been evidenced by Omegna et al. ${ }^{35}$ and Parker et al. ${ }^{33}$; these authors indeed observed that, upon exposure to $\mathrm{NH}_{3}$, part of the $\mathrm{Al}^{\mathrm{V}}$ changed their coordination to $\mathrm{Al}^{\mathrm{IV}}$. Flexible coordination of $\mathrm{Al}$ was associated to its belonging to a silica-alumina phase.

Comparison of the uncalcined samples before and after dealumination (entries $1 \rightarrow 2$ and entries $5 \rightarrow 6$ ) indicates a significant decrease in intensity for all signals after treatment with acetylacetone. This decrease is stronger in the SA25 series (entries $5 \rightarrow 6$ ), which is consistent with the higher decrease of the aluminum concentration observed by elemental analysis after dealumination of SA25. Although all peaks decrease in intensity, one can clearly see that the intensities of the peaks of $\mathrm{Al}^{\mathrm{IV}}$ and $\mathrm{Al}$ decrease in equal proportion while that of $\mathrm{Al}^{\mathrm{V}}$ decreases less. When comparing the spectra of the calcined starting ASAs with those of the dealuminated calcined samples (entries $4 \rightarrow 3 ; 8 \rightarrow 7$ ) one observes that, although all peaks decrease in intensity, the fraction of tetrahedral Al increases and the fraction of pentacoordinated Al decreases for all samples. As this important decrease of the concentration of pentacoordinated Al upon dealumination occurs without significant decrease in the amount 
of acid sites, acidic properties are probably not specifically associated with pentacoordinated $\mathrm{Al}$ in rehydrated samples. It is, however not possible to reach a more precise conclusion in terms of association of one of the three Al coordination with the acidic properties of ASAs, as the fraction of $\mathrm{Al}$, in calcined samples, in any of these coordinations still exceed, and to a large extent, the fraction of acidic $\mathrm{Al}$ atoms. Moreover, the high flexibility of $\mathrm{Al}$ coordination between calcined and uncalcined form of the same sample, makes the association of acidic properties with one $\mathrm{Al}$ coordination even more difficult.

\section{Hydroxyl groups}

For the calcined samples, the total amount of hydroxyls was determined by TGA. Values are reported in Table 3. The total density of $\mathrm{OH}$ groups increases slightly upon dealumination $(+17 \%$, between SA13-H and SA13-HT- $4 \mathrm{~h},+25 \%$ between SA25$\mathrm{H}$ and SA25-HT-4h). This increase is consistent with the increase in the surface area upon dealumination $(+20-30 \%$, see Table 1). Hence, all calcined ASAs have similar surface density of hydroxyls (between 4.5 and $5.1 \mathrm{OH}$ per $\mathrm{nm}^{2}$ ).

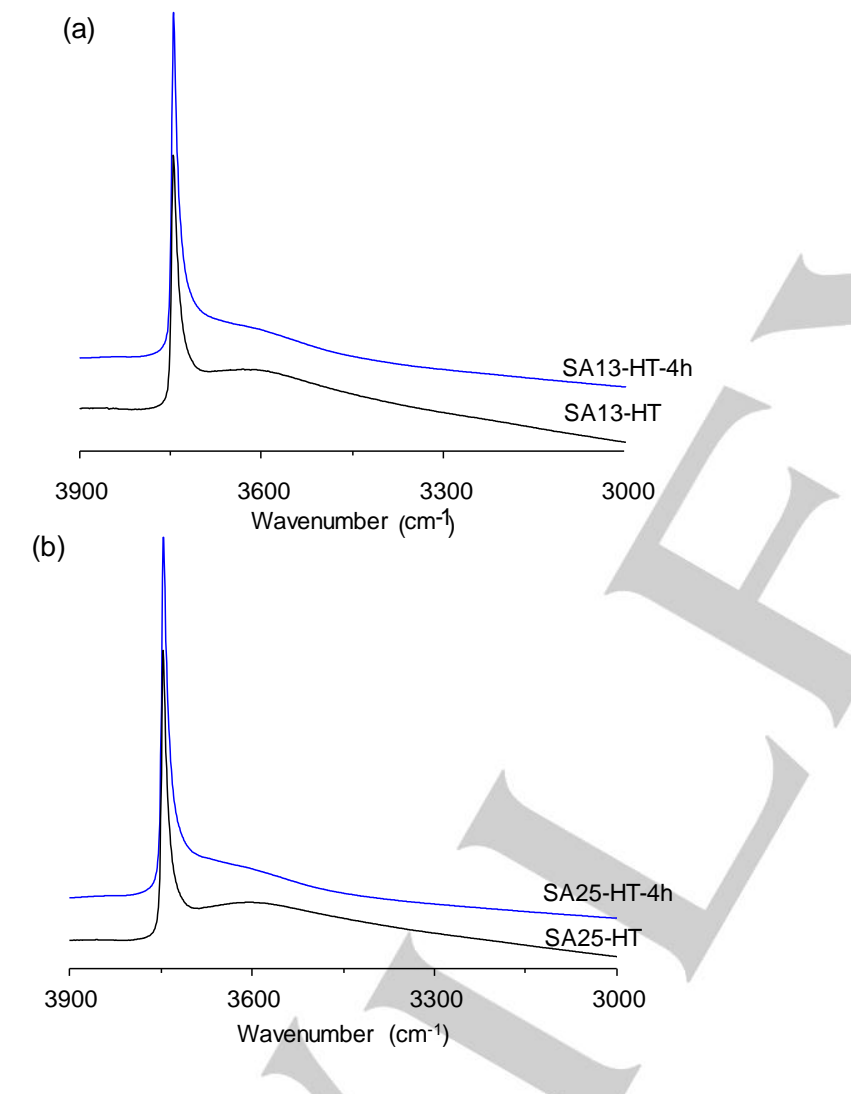

Figure 4: $\mathrm{U}(\mathrm{OH})$ ranges of FTIR spectra of different samples activated at $450^{\circ} \mathrm{C}$ : (a) SA13 series; (b) SA25 series.

Further information on the nature of hydroxyl groups in the samples was acquired by FTIR spectra, as shown in Figure 4. All the samples displayed one sharp band at $3745 \mathrm{~cm}^{-1}$, attributed to accessible, isolated silanol groups. ${ }^{36-40}$ In addition, a broad envelop extending from 3700 to $3300 \mathrm{~cm}^{-1}$ is also detected, generally assigned to hydrogen-bonding $\mathrm{Si}-\mathrm{OH}$ or $\mathrm{Al}-\mathrm{OH}$ groups $(\mathrm{H} \text {-donor })^{41,42}$ and also to disturbed $\mathrm{Si}-\mathrm{OH}$-Al groups. ${ }^{43,44}$. As this broad envelop is more intense on starting ASAs than on dealuminated samples, it likely contains an important contribution of $\mathrm{H}$ bonded $\mathrm{Al}-\mathrm{OH}$ similar to those found in alumina. ${ }^{42}$ Hence, it confirms the presence, in the starting ASAs, of alumina-like debris, that are, at least partly, removed in the dealuminated samples. It is worth mentioning that, even after the removal of a large fraction of non-acidic Al, the identification of a specific signal associated to $\mathrm{Si}-\mathrm{OH}$-Al bridging hydroxyl groups remains impossible. ${ }^{25,45}$

\section{Discussion}

During this discussion we will focus on samples prepared using mild dealumination conditions (samples SAxx-(H-)HT-4h). The mechanism of dealumination of ASA by acetylacetone has not been fully described in the literature but is clearly related to the chelating property of this molecule. The initial step is likely the chelation of surface $\mathrm{Al}$ atoms (and the release of a water molecule), as demonstrated for the interaction of acetylacetone with surface $\mathrm{Al}$ of boehmite by Dickie et al. ${ }^{46}$ The final step is the formation of $\mathrm{Al}(\mathrm{Acac})_{3}$ species and their migration to the solution that has been evidenced by Zanjanchi et al. during the removal of extraframework aluminum atoms from $L$ zeolites. ${ }^{18,20}$ Between these two steps one can postulate that the reactions that occur are similar to those proposed by Chin et al. ${ }^{47}$ for the dissolution of clays in presence of organic acids: the formation of the acetylacetonate complex weakens the $\mathrm{Al}-\mathrm{O}$ bonds and make them more sensitive to hydrolysis by water. The reaction continues until $\mathrm{Al}(\mathrm{Acac})_{3}$ is formed which can be washed out from parent sample resulting in $\mathrm{Al}$ elimination. ${ }^{7,20}$ For the two ASAs, Al elimination is only partial, while acetylacetone is present in excess in solution with regards to their $\mathrm{Al}$ content (considering the formation of $\left.\mathrm{Al}(\mathrm{Acac})_{3}\right)$.

All dealuminated samples have a higher percentage of acidic $\mathrm{Al}$ (based on FTIR of adsorbed pyridine) than the corresponding starting ASA (see Table 1). For the ASA prepared by mild dealumination of ammonium forms, acidic properties are not only preserved but even slightly improved (especially for the mild Brønsted acid sites) and their catalytic properties are improved for 33DMB1 isomerization (by a factor of about 1.5). This is consistent with previous reports on zeolites that concluded to a preferential extraction of non-acidic (extraframework) aluminum ${ }^{7}$, 18,20 and an improvement of acidic properties. This observation tends to indicate that the reactivity of $\mathrm{Al}$ atoms toward extraction by acetylacetone depend on their local environment (either coordination or nature of next nearest neighbors). Nevertheless, the fraction of acidic $\mathrm{Al}$ in dealuminated ASA remains relatively low (8-9\%). Hence, the ability of acetylacetone toward dealumination is limited. Moreover, when dealumination is performed on the ammonium form of ASA, the elimination of $A l$ is more efficient than dealumination performed on the $\mathrm{H}$-form ASA and the total amount of acid sites is either unchanged or slightly increased (whereas it decreases slightly when dealumination is performed on the $\mathrm{H}$-form of the ASA). Hence, dealumination is selective (AcacH only removes weakly bonded, non-acidic $A$ species) when performed in the ammonium form of the ASA and less efficient and only partially selective when performed on the $\mathrm{H}$-form. The difference of efficiency of dealumination between ammonium form and $\mathrm{H}$ form ASAs is likely simply due to the fact that ammonium form is uncalcined and hence contains less condensed Al species. The origin in the difference of selectivity is less straightforward and this effect has not been previously investigated during zeolite dealumination. One could suggest 
either that the $\mathrm{NH}_{4}{ }^{+}$counter-ions somehow protect the acid sites from dealumination, or that acid sites are, in the (uncalcined) ammonium form of ASAs, associated with more condensed $\mathrm{Al}$ species that are less sensitive to extraction by acetylacetone.

For all samples, Al removal is accompanied by an increase in the surface area and, the more Al atoms are removed, the more the surface area increases (see Table 1). This occurs without significant modification in the pore diameter (Figure SI 1) and, for the ASAs stemming from the ammonium form, with an increase in the pore volume. This modification in the textural properties of the ASAs upon dealumination could indicate that alumina-like debris that were blocking the access to a part of the porosity have been removed. The presence of this type of debris in the ASAs and their partial removal by dealumination are confirmed by FTIR with the presence of a broad band at $3500 \mathrm{~cm}^{-1}$ (characteristic $\mathrm{H}$ bonded hydroxyls similar to those found in aluminas) that is clearly visible on the spectra of the starting ASAs, and whose intensity decreases substantially upon dealumination. This increase in the surface area could be at the origin of the moderate increase in the total concentration of acid sites revealed by pyridine desorption experiments.

When comparing the $\mathrm{Al}$ distributions $\left({ }^{27} \mathrm{Al}\right.$ MAS NMR spectroscopy) of the calcined samples (see Figure $\mathbf{3}$ and Table 3), one can see that, for all $\mathrm{Al}$-coordinations, the amount of $\mathrm{Al}$ decreases upon dealumination with acetylacetone. However, the fraction of $\mathrm{Al}^{\mathrm{IV}}$ slightly increases whereas the fraction of $\mathrm{Al}^{\mathrm{V}}$ decreases. As $\mathrm{Al}^{\mathrm{IV}}$ is, in zeolites, associated with $\mathrm{Si}-\mathrm{OH}-\mathrm{Al}$ bridges it is interesting to compare the density of $\mathrm{Al}^{\mathrm{IV}}$ in the dealuminated samples with the density of acid sites. This comparison clearly shows that, even in the dealuminated samples, a large part of the $\mathrm{Al}^{\mathrm{IV}}$ have no acidic properties. Hence, although dealumination with acetylacetone allows increasing significantly the fraction of acidic aluminum (by a factor 2 to 3 ), this fraction remains too low in dealuminated samples to allow identifying clearly acidic aluminum by ${ }^{27} \mathrm{Al}$ MAS NMR. In the same way, the hydroxyls associated to the Brønsted acidity of ASA cannot be identified, even after dealumination, by FTIR spectroscopy.

\section{Conclusion}

Conditions for dealumination of ASA with acetylacetone have been explored and optimal conditions are as follows: dealumination should rather be performed on uncalcined ammonium form of ASA and reflux in toluene during $4 \mathrm{~h}$ leads to optimal dealumination. Under these conditions, dealumination with acetylacetone removes between half and two thirds of the $\mathrm{Al}$ atoms and increases the surface area and pore volume $(+20-$ $30 \%$ ). Moreover, it is fully selective in the sense that the acidic properties (FTIR of adsorbed pyridine) are not decreased (they are even slightly increased) upon dealumination on the ammonium form. The increase in the acidity and/or the change in the textural properties leads to a ca. 1.5 higher conversion of 33DMB1 on the dealuminated ASAs compared to their corresponding parent commercial ASA. The fraction of acidic AI is multiplied by 2 to 3 depending on the starting ASA, but remains low (below $10 \%$ ), indicating that a large fraction of non-acidic $\mathrm{Al}$ is resistant to dealumination with $\mathrm{AcacH}$ (or was not accessible to this reactant). This confirms the application of this molecule as a mild dealuminating agent that had been previously established for zeolites.

The characterization of the starting ASAs and of the dealuminated samples by ${ }^{27} \mathrm{Al}$ MAS NMR reveals that all Al coordinations are subject to dealumination. However, when considering the calcined samples, the fraction of $\mathrm{Al}^{\mathrm{IV}}$ increases whereas the fraction of $\mathrm{Al}^{\mathrm{V}}$ decreases upon dealumination. Nevertheless, the amount of $\mathrm{Al}^{\mathrm{IV}}$, even after dealumination exceed by far (ca. a factor of 5) the amount of acid sites based on FTIR of adsorbed pyridine. The nature of the $\mathrm{Al}$ species removed during dealumination was further investigated by comparing the FTIR spectra of the samples before and after dealumination. Evolution of the spectra is likely related to the removal of alumina-like fragments (identified by broad signals of $\mathrm{H}$-bonded $\mathrm{Al}-\mathrm{OH}$ at ca. $\left.3500 \mathrm{~cm}^{-1}\right)$. Despite a significant increase (2-3 times) in the fraction of acidic $\mathrm{Al}$ upon dealumination, it was not possible to identify hydroxyls in Si-OH-Al bridges on the FTIR spectra. If these bridges are indeed present in ASAs, their fraction is, after dealumination, still too low for their identification.

\section{Supporting Information Summary:}

Supporting information file contains details on material synthesis, material characterization techniques, and conditions for catalytic activity measurement. N2-sorption isotherms are also reported

\section{Acknowledgements}

This work was financially supported by China Scholarship Council and The Guangdong Science and Technology Program (2017B030314002).

Keywords: Dealumination • Amorphous silica-alumina • Acetylacetone treatment.

[1] T. C. Keller, J. Arras, M. O. Haus, R. Hauert, A. Kenvin, J. Kenvin, J. Pérez-Ramírez J. Catal. 2016, 344, 757-767.

[2] A. Corma Chem. Rev. 1995, 95, 559-614.

[3] G. Busca Chem. Rev. 2007, 107, 5366-5410.

[4] J. Scherzer, A. J. Gruia, Hydrocracking science and technology, CRC Press, 1996.

[5] B. Xu, S. Bordiga, R. Prins, J. A. van Bokhoven Appl. Catal., A. 2007, 333, 245-253.

[6] M.-C. Silaghi, C. Chizallet, P. Raybaud Microporous Mesoporous Mater. 2014, 191, 82-96.

[7] S. Kumar, A. Sinha, S. Hegde, S. Sivasanker J. Mol. Catal. A Chem. 2000, 154, 115-120.

[8] J. Van Bokhoven, D. Koningsberger, P. Kunkeler, H. Van Bekkum, A. Kentgens J. Am. Chem. Soc. 2000, 122, 12842-12847.

[9] I. Batonneau-Gener, A. Yonli, S. Hazael-pascal, J. P. Marques, J. M. Lopes, M. Guisnet, F. R. Ribeiro, S. Mignard Microporous Mesoporous Mater. 2008, 110, 480-487.

[10] R. Zhao, Z. Zhao, S. Li, W. Zhang J. Phys. Chem. Lett. 2017, 8, 2323-2327.

[11] S. Li, S.-J. Huang, W. Shen, H. Zhang, H. Fang, A. Zheng, S.-B. Liu, F. Deng J. Phys. Chem. C. 2008, 112, 14486-14494.

[12] R. Baran, Y. Millot, T. Onfroy, J.-M. Krafft, S. Dzwigaj Microporous Mesoporous Mater. 2012, 163, 122-130.

[13] W. Li, J. Zheng, Y. Luo, C. Tu, Y. Zhang, Z. Da Energy \& Fuels. 2017, 31, 3804-3811.

[14] A. Feng, Y. Yu, L. Mi, Y. Cao, Y. Yu, L. Song Microporous Mesoporous Mater. 2019, 280, 211-218.

[15] J. Datka, W. Kolidziejski, J. Klinowski, B. Sulikowski Catal. Lett. 1993, 19, 159-165. 
[16] J. Agudelo, B. Mezari, E. Hensen, S. Giraldo, L. Hoyos Appl.

Catal., A. 2014, 488, 219-230.

[17] W. A. Buckermann, C. B. Huong, F. Fajula, C. Gueguen

Zeolites. 1993, 13, 448-453.

[18] M. Zanjanchi, M. Hemmati Mater. Chem. Phys. 2004, 85, 334339.

[19] M. Hosseini, M. Zanjanchi, B. Ghalami-Choobar, H. Golmojdeh J. Chem. Sci. 2015, 127, 25-31.

[20] M. Zanjanchi, E. Mohabbati J. Mol. Struct. 2003, 645, 171-176.

[21] M. Zanjanchi, A. Razavi Spectrochimica Acta Part A: Molecular and Biomolecular Spectroscopy. 2001, 57, 119-127.

[22] P. P. Man, M. J. Peltre, D. Barthomeuf J. Chem. Soc., Faraday Trans. 1990, 86, 1599-1602.

[23] R. Locus, D. Verboekend, R. Zhong, K. Houthoofd, T. Jaumann, S. Oswald, L. Giebeler, G. Baron, B. F. Sels Chem. Mater. 2016, 28, 7731-7743.

[24] Y. Fan, X. Bao, X. Lin, G. Shi, H. Liu J. Phys. Chem. B. 2006,

110, 15411-15416.

[25] G. Crépeau, V. Montouillout, A. Vimont, L. Mariey, T. Cseri, F. Maugé J. Phys. Chem. B. 2006, 110, 15172-15185.

[26] C. Jia, P. Massiani, D. Barthomeuf J. Chem. Soc., Faraday Trans. 1993, 89, 3659-3665.

[27] C. Flego, I. Kiricsi, C. Perego, G. Bellussi Catal. Lett. 1995, 35, 125-133.

[28] E. Irvine, C. John, C. Kemball, A. Pearman, M. Day, R. Sampson J. Catal. 1980, 61, 326-335.

[29] C. S. John, C. Kemball, R. A. Rajadhyaksha J. Catal. 1979, 57, 264-271.

[30] F. Bautista, J. Campelo, A. Garcia, D. Luna, J. Marinas, A. Romero, M. Urbano React. Kinet. Catal. Lett. 1998, 64, 41-48.

[31] M. R. Guisnet Acc. Chem. Res. 1990, 23, 392-398.

[32] D. Martin, D. Duprez J. Mol. Catal. A: Chem. 1997, 118, 113128.

[33] W. O. N. Parker, S. Wegner Microporous Mesoporous Mater. 2012, 158, 235-240.

[34] M. Baca, E. De La Rochefoucauld, E. Ambroise, J.-M. Krafft, R. Hajjar, P. P. Man, X. Carrier, J. Blanchard Microporous Mesoporous Mater. 2008, 110, 232-241.

[35] A. Omegna, J. A. van Bokhoven, R. Prins J. Phys. Chem. B. 2003, 107, 8854-8860.

[36] A. Janin, M. Maache, J. Lavalley, J. Joly, F. Raatz, N. Szydlowski Zeolites. 1991, 11, 391-396.

[37] H. Ichihashi, M. Kitamura Catal. Today. 2002, 73, 23-28.

[38] G. Heitmann, G. Dahlhoff, W. Hölderich J. Catal. 1999, 186, $12-$ 19.

[39] C. T. Chu, C. D. Chang J. Phys. Chem. 1985, 89, 1569-1571.

[40] I. Kiricsi, C. Flego, G. Pazzuconi, W. J. Parker, R. Millini, C. Perego, G. Bellussi J. Phys. Chem. 1994, 98, 4627-4634.

[41] I. Halasz, E. Senderov, D. H. Olson, J.-J. Liang J. Phys. Chem. C. 2015, 119, 8619-8625.

[42] X. Liu J. Phys. Chem. C. 2008, 112, 5066-5073.

[43] C. Pazé, S. Bordiga, C. Lamberti, M. Salvalaggio, A. Zecchina, G. Bellussi J. Phys. Chem. B. 1997, 101, 4740-4751.

[44] B. Gil, S. I. Zones, S.-J. Hwang, M. Bejblová, J. Cejka J. Phys. Chem. C. 2008, 112, 2997-3007.

[45] M. Williams, B. Fonfé, C. Sievers, A. Abraham, J. Van

Bokhoven, A. Jentys, J. Van Veen, J. Lercher J. Catal. 2007, 251, 485-496.

[46] S. A. Dickie, A. J. McQuillan Langmuir. 2004, 20, 11630-11636.

[47] P.-K. F. Chin, G. L. Mills Chem. Geol. 1991, 90, 307-317. 


\section{Entry for the Table of Contents}

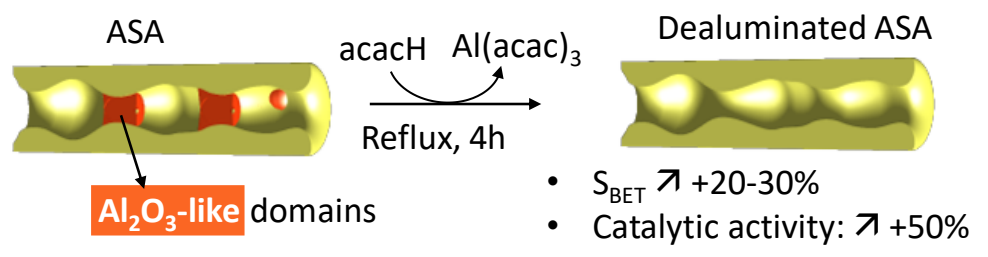

Commercial amorpous silica-aluminas (ASAs) have been dealuminated using acetylacetone (acacH). These mild dealumination conditions allow removing $1 / 2$ to $2 / 3$ of $\mathrm{Al}$ atoms, while increasing the surface area and preserving the acid sites. Dealuminated samples have a 1.5 higher activity for 3,3-Dimethyl-1-butene (33DMB1) isomerization reaction.

Institute and/or researcher Twitter usernames: ((optional)) 